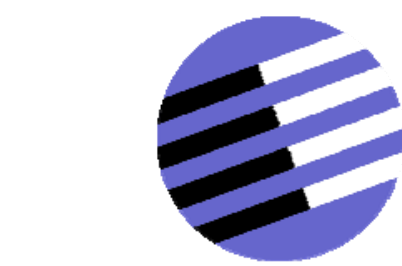

GOVERNANCE AND THE EFFICIENCY

OF ECONOMIC SYSTEMS

GESY

\begin{tabular}{|} 
Discussion Paper No. 148 \\
What do deficits tell us about \\
debt? Empirical evidence on \\
creative accounting with fiscal \\
rules in the EU \\
Jürgen von Hagen* \\
Guntram B. Wolff**
\end{tabular}

January 2006

*J ürgen von Hagen, Institut für Internationale Wirtschaftspolitik, University of Bonn, CEPR, and Indiana University, Walter-Flex-Str. 3, 53113 Bonn, Germany, Tel: +49 22873 9199, vonhagen@uni-bonn.de

**Guntram B. Wolff, Deutsche Bundesbank, ZEI-University of Bonn and UCIS-University of Pittsburgh, WilhelmEpstein-Straße 14, 60431 Frankfurt am Main, Germany, Tel: +49 699566 3353, guntram.wolff@bundesbank.de

Financial support from the Deutsche Forschungsgemeinschaft through SFB/TR 15 is gratefully acknowledged. 


\title{
What do deficits tell us about debt? Empirical evidence on creative accounting with fiscal rules in the $\mathrm{EU}$
}

\author{
Jürgen von Hagen ${ }^{*}$ and Guntram B. Wolff ${ }^{* *}$ \\ Frankfurt, January 18, $2006^{+}$
}

\begin{abstract}
:
Fiscal rules, such as the Excessive Deficit Procedure and the Stability and Growth Pact (SGP), aim at constraining government behavior. Milesi-Ferretti (2003) develops a model in which governments circumvent such rules by reverting to creative accounting. The amount of this depends on the reputation cost for the government and the economic cost of sticking to the rule. We provide empirical evidence of creative accounting in the European Union. We find that the SGP rules have induced governments to use stock-flow adjustments, a form of creative accounting, to hide deficits. The tendency to substitute stock-flow adjustments for budget deficits is especially strong for the cyclical component of the deficit, as in times of recession the cost of reducing the deficit is particularly large.
\end{abstract}

Keywords: Fiscal rules, stock-flow adjustments, debt-deficit adjustments, stability and growth pact, excessive deficit procedure, ESA 95

JEL-Classifications: E62, H61, H62, H 63, H 70

\footnotetext{
* Institut für Internationale Wirtschaftspolitik, University of Bonn, CEPR, and Indiana University, Walter-FlexStr. 3, 53113 Bonn, Germany, phone: +49 228739199 email: vonhagen@uni-bonn.de

** Deutsche Bundesbank, ZEI-University of Bonn and UCIS-University of Pittsburgh, Wilhelm-Epstein-Straße 14, 60431 Frankfurt am Main, Germany, phone: +49 699566 3353, email: guntram.wolff@bundesbank.de

${ }^{+}$We would like to thank the anonymous referees, Jörg Breitung, Kirsten Heppke-Falk, Heinz Herrmann, Jana Kremer, Wolfgang Lemke, Rolf Strauch, and the fiscal policy departments of the ECB and the Deutsche Bundesbank for many, very helpful discussions. Research assistance by Sascha Heise is gratefully acknowledged. Remaining errors are ours. The opinions expressed in this paper do not necessarily reflect the views of the Deutsche Bundesbank or its staff. Financial support from the DFG through SFB TR 15 is gratefully acknowledged.
} 


\section{Introduction}

Fiscal rules aim at constraining the behavior of governments. They are introduced to reduce rent seeking behavior of politicians, to mitigate common pool problems, and, ultimately, to prevent undesired fiscal outcomes (von Hagen 2002). The European Economic and Monetary Union (EMU) provides an important example. Governments in a monetary union have an incentive to run excessive deficits and accumulate excessive debts. High deficits and debt levels increase the pressure on the central bank to monetize them and create inflation. Anticipating this, the private sector adjusts inflation expectations upwards, resulting in higher nominal interest rates. ${ }^{1}$ But since the (expected) inflation from monetizing a given amount of government debt is spread over all members of the monetary union, the cost of excessive deficits and debts in terms of higher inflation and interest rates is smaller, and the incentive for profligate fiscal behavior is larger, for each individual government than in the case of a national currency.

Recognizing this problem, the governments of the EMU member states have adopted a set of rules to strengthen fiscal discipline. These fiscal rules feature a limit on the annual general government budget deficit of three percent of GDP and a limit on generalgovernment debt of 60 percent of GDP. In practice, the deficit limit is considered to be the more important one in the policy debate.

Fiscal rules necessarily refer to specific budgetary items and data. Governments can shift fiscal expenditures off the budget, i.e., revert to creative accounting, to circumvent such rules. Milesi-Ferretti (2003) analyzes the effect of fiscal rules on creative accounting in a model based on von Hagen and Harden (1995, 1996). In this model, the government has an incentive to circumvent the rule by hiding fiscal policies in less visible positions. The likelihood of creative accounting decreases in the cost the government has to bear if the cheating is detected. Furthermore, creative accounting is the more likely, the higher the economic costs of sticking to the rule are. If strict rules prevent the appropriate response of fiscal policy to (business cycle) shocks, the likelihood of creative accounting increases in the model. ${ }^{2}$ The

\footnotetext{
${ }^{1}$ In the absence of perfect international capital mobility, high debt levels may also lead to higher real interest rates.

${ }^{2}$ Milesi-Ferretti shows that more transparency of the budget is only desirable at very low levels of budget transparency, since in this case, governments tend to let the budget fluctuate too much. At high levels of
} 
optimal design of a fiscal rule should take the possibility of creative accounting into account. As a result, an optimal rule is likely to be stricter in the presence than in the absence of creative accounting.

A number of authors have investigated the effects of fiscal rules. The literature generally assesses the effect on the fiscal aggregate constrained by the rules, and, in a second step, the effect on other, non-constrained fiscal positions. von Hagen (1991) empirically investigates the effects of fiscal restraints on state budgets in the US and shows that they induce substitution out of restricted into non-restricted debt instruments. Bunch (1991) and Sbragia (1996) show that debt limits on state or local governments in the US have led to an increased use of non-constrained public authorities to issue debt. Poterba (1994) shows that more restrictive state fiscal rules are correlated with more rapid fiscal adjustment to unexpected deficits. Kiewiet and Szakaly (1996) show that restrictive provisions to limit debt issuance at the state level result in the devolution of debt issuance to governments at the local level. Bohn and Inman (1996) find for a sample of 47 US states that only balance requirements enforced as constitutional (not statutory) constraints by an independently elected (not politically appointed) state supreme court have significant positive effects on a state's general fund surplus. Strauch (1998) shows that constitutional expenditure limits in the US induce a shift of expenditures from the (constrained) current budget to the (unconstrained) investment budget.

Dafflon and Rossi (1999) survey the accounting tricks governments used in the run-up to the Euro. They find that the methodological rules of the European system of accounts are weak and that numerous countries have used tricks to qualify for EMU membership. Milesi-Ferretti and Moriyama (2004) find that in the run up to EMU membership reductions in government debt were accompanied by strong decumulations of government assets. These authors argue that, in the run up to the Euro, the fiscal rules of Maastricht led to significant fiscal operations, which improved the official figures but had no effect on the actual fiscal position of the government. The bottom line of this research is that fiscal rules have an effect on the fiscal aggregates to which they refer. However, governments try to compensate for the loss of flexibility due to the rule by shifting fiscal activities from restricted to non-restricted instruments.

transparency, a further increase of transparency would hinder the working of automatic stabilizers too much and is therefore not optimal. 
In this paper we extend this line of research and test the model by Milesi-Ferretti (2003). In particular, we document stock-flow adjustments in the European Union, which are computed as the annual changes in debt levels minus the annual budget deficits. Positive stock-flow adjustments imply that the debt level increases by more than it should given the deficit. While stock-flow adjustments are a common feature of public finances due to accounting issues, they should generally not generate a systematic bias between the stock of debt outstanding and the sum of all budget deficits over time. In many EU states, however, we find that stockflow adjustments are persistent and that the difference between debt stocks and accumulated deficits is large. We interpret this as a first indication of a systematic strategic use of stockflow adjustment. We then investigate the effect of the fiscal rules in Europe, more precisely of the excessive deficit procedure (EDP) and the Stability and Growth pact (SGP). The SGP in particular puts a large weight on the deficit limit in the EMU, since, in the European public debate, the loss of political reputation is significant for countries breaching the deficit limit but not for countries breaching the debt limit. As greater attention is paid to the deficit, we expect that governments try to shift budget deficits (restricted) to off-budget deficits (nonrestricted) in form of stock-flow adjustments. We find that stock-flow adjustments are systematically related to deficits after the fiscal rules became effective. Recorded deficits have been lowered by increasing stock-flow adjustments. This effect is especially pronounced, when the fiscal rule is binding, i.e., when governments desire to run deficits in excess of the formal limits. In addition, we confirm the prediction by Milesi-Ferretti (2003) that the use of creative accounting varies over the business cycle.

The remainder of the paper is organized as follows: The next section presents accounting identities, data and measurement issues and the amount of stock-flow adjustment in the European Union. In section 3, we develop our estimation strategy and present the evidence on creative accounting in the EU. Section 4 concludes.

\section{Deficits and debt: stock-flow adjustments}

\subsection{Accounting identities}

Standard textbooks in macroeconomics give equation (1) as the fundamental relationship between deficits, $D$, and debt, $B$. In this definition, the deficit is calculated as the difference between expenditure and revenue, where expenditure includes interest payments. 


$$
B_{t}=B_{t-1}+D_{t}
$$

From this equation, the current debt level is equal to the accumulated past deficits plus the initial debt level (equitation 2).

$$
B_{t}=B_{t-n}+\sum_{i=0}^{n-1} D_{t-i}
$$

In practice, equation (1) does not always hold, if the deficit is defined as the difference between budgetary expenditures and revenues. A residual can be computed according to

$$
B_{t}-B_{t-1}-D_{t}=S F A_{t}
$$

This residual is called stock-flow adjustment, or debt-deficit adjustment. A positive stockflow adjustment means that the stock of government debt has increased between period $t$ and $(t-1)$ by more than the budget deficit in period $t$ indicates. The official definition treats stock-flow adjustments as a statistical residual. As the European Commission states, stockflow adjustments "result primarily from financial operations, e.g., debt issuance policy to manage public debt, privatization receipts, impact of exchange rate changes on foreign denominated debt. In general, these should tend to cancel out over time. However, large and persistent stock-flow adjustments (especially if they always have a negative impact on debt developments) should give cause for concern, as they may be the result of the inappropriate recording of budgetary operations and can lead to large ex-post upward revisions of deficit levels. (European Comission, DG for Economic and Financial Affaires 2003, p. 79). ${ }^{3}$

\subsection{Data and measurement issues}

Deficit and debt figures very much depend on their precise definition and measurement (e.g., Blejer and Cheasty, 1991). In this article we use data published in the AMECO database, which is based on Eurostat data and serves as the basis of the EDP and the SGP. Eurostat follows the ESA 95 accounting standard to measure deficits and debt. The data refer to the general consolidated government sector, which includes the central, state and local

\footnotetext{
${ }^{3}$ For recent evidence on upward revisions because of persistent stock-flow adjustments, see Balassone, Franco, and Zotteri (2004).
} 
government and the social security sector. ${ }^{4}$ The definition of debt under the EDP, on which our data is based, slightly differs from ESA 95, as debt is recorded at face value in the EDP and not at market value as in the ESA 95. ${ }^{5}$ In general, the difference between deficits and the change in debt levels results from the fact that public debt is a gross concept, while deficits are a net concept. For example, if a government issues debt and deposits the proceeds in a bank account, the effect if the deficit is zero, while gross debt increases.

Stock-flow adjustments result from five main issues: (1), issuance of zero coupon bonds. Consider a bond which is issued for 90 Euro to cover a deficit and has a face value of 110 . This operation is recorded as a deficit of 90 and a stock-flow adjustment of 20 in the year of issuance, since the debt level at face value increases by 110. In the following 4 periods until maturity, an interest of 5 accrues, impacting on the deficit, the debt level stays constant, the stock-flow adjustment is -5 in each period. As can be seen, stock-flow adjustments of zero coupon issuances should cancel out over time. (2), revaluation of debt denominated in foreign currency changes the face value of the debt, without having any impact on the budget.

Revaluation of foreign denominated debt should only matter if a country has a depreciating currency over a long period. Foreign denominated debt does not play any significant role in any of the EU 15 countries. Exchange rate effects are less than 0.2 percent of GDP in general (ECB 2004, Table 6.3.2). (3), time-of-recording effects: Deficits are measured in accrual terms, while debt is a cash concept. For example, when UMTS licenses are sold, this has an effect on the deficit in the year of selling, so when the receipts accrue, however, debt is only reduced when the (cash) receipts are used to buy back the debt. The time of recording effect should usually cancel out after some years. ${ }^{6}$ The only two remaining issues, where long and persisting positive stock-flow adjustments can be expected, are, (4), equity injections in and privatization of public companies and, (5), transactions in financial assets. Selling of financial assets reduces gross debt, however it has no effect on the deficit according to the rules of the EDP and the SGP.

\footnotetext{
${ }^{4}$ For details on the precise definitions see Eurostat 2002, p.8-16).

${ }^{5}$ Debt means total gross debt at nominal value outstanding at the end of the year and consolidated between and within the sectors of general government" (Eurostat 2002, p. 190).

${ }^{6}$ Interest accrued affects net borrowing/net lending. "For government debt under EDP (at nominal value, not including accrued interest) interest due but not paid is to be recorded under Other accounts payable (F.79), as long as it is not paid (ESA95, §5.131). In the EDP, interest arrears under Other accounts payable are not accounted for in the government debt" (Eurostat 2002, p. 199). Thus, interest payments are recorded in the deficit when they accrue, even if they are not paid yet, and should in this case lower stock-flow adjustments as they are not recorded in the debt according to EDP. In the long-run, interest payments are without effect on stock-flow adjustment.
} 
Capital injections into public companies are an important tool to hide deficits and incur increases in the debt level, resulting in positive stock-flow adjustments. The operation must be recorded as an equity injection or transaction in shares and other equity, i.e., the government has to declare to have a lasting economic interest in the public company in the sense of intending to receive a market interest rate. If the injection is used to cover recurring losses of the public company, it should be recorded as a current transfer, which leaves the stock-flow adjustment unaffected. In practice, it is very difficult to control whether injections have been correctly recorded. ${ }^{7}$ Capital injections can therefore be used to shift public expenditure from the (deficit-relevant) state sector to public companies. Thereby, the deficit is reduced, while the change in debt level captures the "true" public spending. A positive stock-flow adjustment results. ${ }^{8}$ These mechanisms have also attracted the attention of the European Commission. Joaquín Almunia, EU monetary affairs commissioner, has recently claimed that governments disguise the scale of their budget deficits. ${ }^{9}$

\subsection{Debt vs. accumulated deficits: descriptive evidence}

Persistent stock-flow adjustments can be a matter of concern (European Commission, DG for Economic and Financial Affairs 2003, p.79).. A natural test for the persistence of stock-flow adjustments is to compare the debt level (column B of Table (1)) with the accumulated deficits as described in equation (2), i.e., the sum of the debt level of 1980 and all budget deficits between 1980 and 2003 as a percent of 2003 GDP (column C of Table (1)), both measured in percent of GDP of 2003. Calculating the difference of actual debt levels and accumulated deficits in percent of GDP (B-C) shows that most EU countries have regularly had positive stock-flow adjustments. Finland and Greece have 64 and 43 percentage points of GDP more debt than their budget data suggest, followed by Denmark (30), Luxembourg (29), Germany (15), and Austria (14). The cases of Finland and Luxembourg are noteworthy as the debt level should be negative if one added the deficits and surpluses. In both countries, budget surpluses have thus been used in the last years to buy assets instead of paying back debt.

\section{Insert Table 1 here}

\footnotetext{
${ }^{7}$ The sale of non-financial assets reduces the deficit, as it is recorded as negative investment or more precisely negative public "gross fixed capital formation".

${ }^{8}$ Public-private partnerships can also be used to hide deficits. However, they will not automatically be seen in the form of stock-flow adjustments.

${ }^{9}$ http://news.ft.com/cms/s/cd1192f0-35cd-11da-903d-00000e2511c8.html.
} 
Off-budget debt accumulation in the form of stock-flow adjustments thus plays a considerable role in most EU-15 countries, with substantial variations across countries. ${ }^{10}$ Stock-flow adjustments constitute a significant part of the overall debt accumulation in the member states of the EU. The (unweighted) annual average stock-flow adjustment in the EU amounts to 1.56 percent of GDP in the period 1981-2003. As Figure (1) shows, it exceeds three percent of GDP in some years. Average stock-flow adjustments had a declining trend until 1996. This negative trend may reflect the persistent efforts of European governments to comply with the debt limit imposed by the Maastricht Treat. Since 1996 the average SFA has risen again to more than two percent in 2001. A similar pattern can be seen for the average of three large EU economies, France, Germany and Italy. As argued by Milesi-Ferretti and Moriyama (2004), EU governments thus reduced their gross debt by selling assets rather than by improving the net-financial position of the government through lower deficits. This was a convenient way to fulfill the Maastricht criterion of falling debt levels for the highly indebted countries.

Figure 1:Average stock-flow adjustments in percent of GDP.

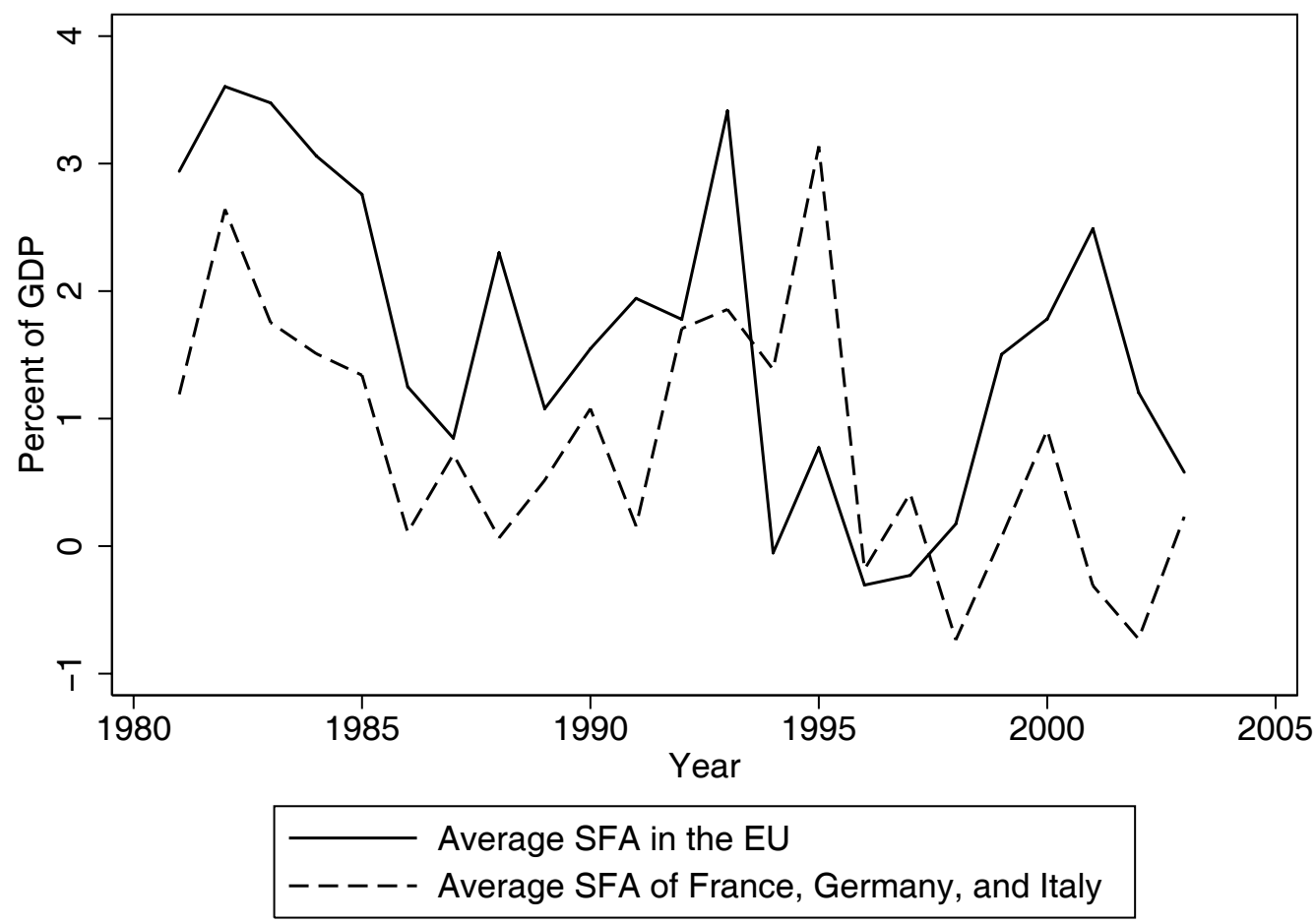

Source: Ameco database, authors’ calculation.

\footnotetext{
${ }^{10}$ Also the US has a significantly higher debt level than given by the sum of deficits with a difference of 9 percent of GDP in the period 1980-2003.
} 
Stock-flow adjustments of selected countries deserve particular attention. In Germany, the debt level increased by more than 6 percent of GDP in addition to the deficit in 1995, when the German federal government officially assumed the debt previously hidden in the Treuhandanstalt, the holding company of former East German industries. ${ }^{11}$ In Greece, the stock-flow adjustment reached almost 19 percent in 1994, when the debt of the Greek government at the Bank of Greece was officially recorded as public debt. Finland experienced a stock-flow adjustment of 12 percent in 1992 related to the banking crisis it suffered in connection with the currency crisis of the Markka. The negative stock-flow adjustment of Belgium in 1996 is noteworthy. It reflects a booking operation designed to show that Belgium had a declining debt level and, therefore, qualified for EMU membership (Laughland and Paul 1997). In summary, we find significant evidence for persistent and systematic use of stockflow adjustments.

\subsection{Stock-flow adjustments and creative accounting}

Persistent, positive stock-flow adjustments allow governments to accumulate public debt in excess of what is implied by the annual budget deficits. But they nay also be the result of net acquisitions of financial assets in times of budget surpluses. For example, a government using budget surpluses to accumulate reserves in pension insurance funds would have long lasting positive stock-flow adjustments, without hiding away any deficits. To test for this possibility, we check the correlation between the net acquisition of financial assets and stock-flow adjustments, both in percent of GDP, for the period and countries for which data were available, namely for the period 1996-2002, and Austria, Belgium, Finland, France, Germany, Italy, Netherlands, Portugal, and Spain. The resulting coefficient is 0.21 and is not statistically significant. $^{12}$

But even if stock-flow adjustments reflect asset acquisitions, this could still be a way to change official deficit figures. The data on asset acquisition do not reflect the evolution of the

\footnotetext{
${ }^{11}$ In fact, when the Treuhandanstalt was dissolved, the debt of 204 billion DM were carried forward to the Erblastentilgungsfond. The German statistical office wanted to classify this as an increase of the debt and of the deficit. Theo Waigel, the finance minister at the time, however objected and argued that this debt should not impact on the deficit according to the Maastricht criteria. Eurostat accepted this view, which explains the large stock-flow adjustment in this year (Münster, 1997).

12 The correlation coefficients have to be interpreted carefully as the data on assets refer to the non-consolidated general government sector, while the deficit and debt data are consolidated across government sectors. The data source for net asset accumulation is Annual National Financial Accounts (ANFA) dataset.
} 
value of these assets. It is possible, for example, that the asset acquisition is only a hidden subsidy, or capital injection into a (public) company. The public company could then engage in standard public expenditure, driving down the value of its assets without any impact on the gross debt level of the government, nor on net borrowing. We therefore conclude that the stock-flow adjustments observed in Europe reflect to some extent at least systematic creative accounting.

\section{Fiscal rules and stock-flow adjustments}

\subsection{Approach}

Milesi-Ferretti (2003) argues that fiscal rules can induce governments to engage in "bad" or even "ugly" creative accounting. To test this proposition, we investigate the relationship between deficits and stock-flow adjustments. The SGP is a fiscal rule with a particular focus on budget deficits. It requires the deficit to stay below the three percent reference value and to have a budget close to balance in the medium term. Following Milesi-Ferretti (2003), the tendency to use stock-flow adjustments to keep reported deficits lower than the actual increase in public debt should have increased since the inception of the SGP. It should be particularly pronounced, when countries are close to breaching the three percent limit and when the cost of reducing the deficit is high, i.e., in times of recessions.

More specifically, consider a government allocating expenditures and taxes optimally over time as in Milesi-Ferretti (2003). Assume that the government has derived an optimal change in government debt, $\Delta_{t}^{*}$, for period $\mathrm{t}_{\mathrm{t}}$. If the actual change in government debt deviates from the optimal change, the government suffers a cost of $K_{1 t}=\alpha_{t}\left(B_{t}-B_{t-1}-\Delta_{t}^{*}\right)^{2}$. The parameter $\alpha_{t}$ may vary over time, reflecting, e.g., different costs of deviating from the optimal fiscal stance at different points of the business cycle. In the absence of any constraint on the government budget deficit, the actual change in government debt equals the budget deficit, $D_{t}$, plus an exogenous, random stock-flow adjustment, $\varepsilon_{t}$, due to timing effects etc., with $E_{t-1}\left(\varepsilon_{t}\right)=0$, where $E_{t-1}$ denotes the expected value based on information available in period t-1. Thus, $B_{t}-B_{t-1}=D_{t}+\varepsilon_{t}=\Delta_{t}^{*}+\varepsilon_{t}$ Note that, by assumption, the budget deficit and the observed stock-flow adjustment are uncorrelated. 
Assume now that there is a deficit limit, $D L$ applying to the observed budget deficit. If the government violates the deficit limit, it suffers a cost increasing in the size of the violation, $K_{2 t}=\beta_{0}+\beta_{1}\left(D_{t}-D L\right)^{2}$ for $D_{t}>D L$ and $K_{2 t}=0$ otherwise. Finally, assume that the government can use stock-flow adjustments strategically to increase government debt deliberately by more than the budget deficit. Let the strategic component of stock-flow adjustments be $S_{t}$. Thus, the total stock-flow adjustment observed ex post is $S F A_{t}=S_{t}+\varepsilon_{t}$. With a given probability p, the strategic use of stock-flow adjustments will become known to the public. If that happens, the government suffers a reputational cost $K_{3 t}=\gamma_{0}+\gamma_{1} S_{t}$ for $S_{t}>0$, and $K_{3 t}=0$ otherwise.

The government now has two instruments to implement the optimal change in government debt, budget deficits and strategic stock-flow adjustments. Formally, it minimizes the cost function $K_{t}=K_{1 t}=K_{2 t}+K_{3 t}$ subject to the constraint $B_{t}-B_{t-1}=D_{t}+S_{t}+\varepsilon_{t}$ and $D_{t}<D L$. As long as the deficit limit is not binding, the government will not use stock-flow adjustments strategically, and choose $D_{t}=E_{t-1}\left(B_{t}-B_{t-1}\right)=\Delta_{t}^{*}$. Assuming that the cost of deviating from the optimal change in government debt is known when $D_{t}$ and $S_{t}$ are chosen, we obtain the following solutions for the budget deficit and the strategic stock-flow adjustment:

$$
D_{t}^{*}=\frac{\alpha_{t}\left(\Delta_{t}^{*}-S_{t}^{*}\right)+\beta_{1} D L}{\beta_{1}+\alpha_{t}},
$$

$$
S_{t}^{*}=\frac{\alpha_{t}\left(\Delta_{t}^{*}-D_{t}^{*}\right)}{\gamma_{1}+\alpha_{t}}
$$

Thus, if the cost of deviating from the optimal change in government is small, $\alpha_{t}^{2}<\beta \cdot \gamma$, the change in government debt will be smaller than in the absence of the debt limit, and the actual deficit lies between the unconstrained deficit and the deficit limit. Furthermore, if the deficit limit is binding, the actual deficit and the strategic part of the stock-flow adjustment are negatively correlated. That is, the larger the strategic stock-flow adjustment, the smaller the observed budget deficit. This correlation increases, when the economic cost of deviating from the optimal change in government debt becomes large. Subsequently, we focus on this 
correlation to test for the strategic use of stock-flow adjustments to hide government deficits under EMU.

Based on these considerations, we do not expect a systematic relationship between stock-flow adjustments and the deficit before 1998, when the SGP became binding. After 1998, however, governments may have used stock-flow adjustments actively to control the deficit. SFA becomes a policy variable, influencing the deficit level. Thus, we expect a significant negative relation between stock-flow adjustments and the budget deficit for the period 1998-2003, when EU countries had to comply with the SGP. In a first step we calculate the correlation coefficients between stock-flow adjustments and deficits in the two periods for all EU 15 countries. In the first period (1980-1997), the correlation is -0.03 and insignificant, in the second period (1998-2003) it is -0.53 and statistically significant.

This simple correlation analysis allows neither for country-specific effects nor for autocorrelation in the variables caused by business cycle fluctuations. We therefore employ the following more elaborate panel econometric approach. From identity (3), we know that the change of the total debt level in percent of GDP in country $i$ at time $t\left(\Delta b_{i t}=\frac{B_{i t}-B_{i, t-1}}{Y_{i t}}\right)$ is the sum of stock-flow adjustment in percent of GDP $\left(s f a_{i t}\right)$ and the deficit in percent of GDP $\left(d_{i t}\right)$, i.e., $\Delta b_{i t}=s f a_{i t}+d_{i t}$. Estimating the following equation

$$
\Delta b_{i t}=\alpha_{0}+\alpha_{1} s f a_{i t}+\varepsilon_{i t}
$$

gives $\alpha_{1}$ as:

$$
\begin{aligned}
\alpha_{1} & =\frac{\operatorname{cov}\left(\Delta b_{i t}, s f a_{i t}\right)}{\operatorname{var}\left(s f a_{i t}\right)} \\
& =\frac{\operatorname{cov}\left(s f a_{i t}+d_{i t}, s f a_{i t}\right)}{\operatorname{var}\left(s f a_{i t}\right)} \\
& =\frac{\operatorname{var}\left(s f a_{i t}\right)+\operatorname{cov}\left(d_{i t}, s f a_{i t}\right)}{\operatorname{var}\left(s f a_{i t}\right)} \\
& =1+\frac{\operatorname{cov}\left(d_{i t}, s f a_{i t}\right)}{\operatorname{var}\left(s f a_{i t}\right)}
\end{aligned}
$$


If $\alpha_{1}=1$, we know that the covariance between deficits and stock-flow adjustments is zero. A coefficient smaller (larger) one implies a negative (positive) covariance between $s f a$ and $d$. The following regression allows to estimate the impact of the fiscal rule.

$\Delta b_{i t}=\alpha_{0}+\alpha_{1} s f a_{i t}+\alpha_{2} T_{t}+\alpha_{3} s f a_{i t} \cdot T_{t}+\mu_{i}+\varepsilon_{i t}$

where $T_{t}$ is a dummy that takes a value of 1 for the years 1998-2003 and zero otherwise. The coefficient $\alpha_{2}$ measures the effect of the dummy (the fiscal rule) on the level of the change in debt levels. $\alpha_{3}$ measures the effect of the fiscal rule on the relationship between $s f a$ and the change in debt levels. The coefficient $\alpha_{3}$ gives the impact of the fiscal rule on the covariance between the deficit and $s f a$. Given that our hypothesis of no relation between $d$ and $s f a$ before the introduction of the rule holds true, i.e., $\alpha_{1}=1$,. the coefficient $\alpha_{3}$ then directly measures the covariance between deficits and stock-flow adjustments after 1997. A negative coefficient $\alpha_{3}$ implies, that the covariance between deficits and stock-flow adjustments became negative in the second period. An increase in the stock-flow adjustment $\left(s f a_{i t}\right)$ would therefore result in a lower deficit.

In order to separate the effects of structural from cyclically adjusted deficits, we specify an alternative regression model:

$\Delta b_{i t}=\beta_{0}+\beta_{1} d_{i t}+\beta_{2} T_{t}+\beta_{3} d_{i t} \cdot T_{t}+\mu_{i}+\varepsilon_{i t}(9)$

where $T_{t}$ is again a dummy that takes a value of 1 for the years 1998-2003 and zero for the years before. The effect of the fiscal rules (the treatment effect) can then be calculated accordingly. A negative coefficient $\beta_{3}$ implies, that an increase in the deficits $\left(d_{i t}\right)$ results in a lower stock-flow adjustment as a consequence of the introduction of the fiscal rule. The coefficients $\beta_{3}$ and $\alpha_{3}$ should be of the same sign as they reflect the same covariance. To capture the effect of the structural and the cyclical part of the deficit, we augment equation 9 and estimate 
$\Delta b_{i t}=\beta_{0}+\beta_{1} T_{t}+\beta_{2} d_{i t}^{s}+\beta_{3} d_{i t}^{s} \cdot T_{t}+\beta_{4} d_{i t}^{c}+\beta_{5} d_{i t}^{c} \cdot T_{t}+\mu_{i}+\varepsilon_{i t}$

where $d^{S}$ specifies the cyclically adjusted (structural) deficit, whereas $d^{c}$ is the cyclical part of the deficit. We expect the coefficient $\beta_{3}$ to be of similar size as the coefficient $\alpha_{3}$ since the largest part of the deficit is structural. For $\beta_{5}$ the model by Milesi-Ferretti (2003) predicts a larger coefficient, i.e., we expect creative accounting to be used strongly with the business cycle.

To test whether creative accounting is most prevalent, when the rule is binding, we further augment the approach. We separate empirically the effect of the introduction of the rule captured by the time dummy from the effect the rule has on governments, whose policy objective is to spend more than 3 percent of GDP in excess of their revenues. Since in this case, we expect countries to employ SFA systematically to lower the deficit, we cannot identify the policy objective by looking at the deficit. Instead, we identify the intention of the government to breach the three percent limit by $\frac{\Delta B_{t}}{Y_{t}} \geq \frac{\overline{D_{t}}}{Y_{t}}=3 \%$ if the fiscal rule is in place. If the rule applies only to those countries, which breach the 3 percent criterion, then only those countries intending to increase their debt level by more than 3 percent should engage in creative accounting. Countries below that limit should show no particular attempt to engage in creative accounting. ${ }^{13}$ This means that the correlation between stock-flow adjustments and deficits should be negative when the rules are in place (second period) and the change of the debt level is above 3 percent. It should be zero, when the change of the expected debt level is below 3 percent.

The following model is estimated to test this hypothesis, $\Delta b_{i t}=\gamma_{0}+\gamma_{1} s f a_{i t}+\gamma_{2} T_{t}+\gamma_{3} T_{t} \cdot s f a_{i t}+\gamma_{4} R_{i t}^{e}+\gamma_{5} T_{t} \cdot R_{i t}^{e}+\gamma_{6} R_{i t}^{e} \cdot s f a_{i t}+\gamma_{7} T_{t} \cdot R_{i t}^{e} \cdot s f a_{i t}+\mu_{i}+\varepsilon_{i t}$ where $R_{i t}^{e}=1$ if $E\left(\Delta b_{i t} \mid I_{t-1}\right)>3$ is a dummy taking the value of 1 if the expected change in debt is larger than 3 percent of GDP. In this view, governments will engage in creative

\footnotetext{
${ }^{13}$ In fact, if $\frac{\Delta B_{t}}{Y_{t}}<3$ and SFA $>0$, we can be sure, that the government meets the criteria set by the pact.
} 
accounting if they expect their newly accumulated debt to be above three percent. We therefore expect $\gamma_{7}$ to be significantly negative, implying a strong negative correlation between sfa and deficits, when the rules are in place (second period) and binding (expected debt level change larger 3). The effect of the introduction of the rule, given by $\gamma_{3}$, should become insignificant, if we assume that the rule is not binding when countries have a deficit below three percent. Finally, as given by the accounting identity, we expect sfa to contribute as above one to one to an increase of the debt level, i.e., $\gamma_{1}=1$ and $\gamma_{6}=0$.

An obvious problem of these approaches is the simultaneous equation bias, which renders the least square estimator inconsistent (Gujarati (1995, pp. 642) and Greene (2000, pp. 652)). We therefore ran two stage least square instrumental variable estimators and instrumented with the lag of the variables. To address the endogeneity of $R$, we instrumented the realized $R_{i t}$ with the appropriate lags. However, in this approach we cannot take account of serial correlation. Serial correlation can be expected as the change in the debt level $\Delta b$ depends on the business cycle.

We therefore specify a dynamic panel model with the lagged dependent variable included as a regressor. We use the dynamic panel estimator by Arellano and Bond (1991), restricting the number of lagged levels to 5 in the instrument set. ${ }^{14}$ To address the simultaneous equation bias and endogeneity bias, we explicitly allow $s f a, T \cdot s f a$, and for the extended approach in addition $R \cdot s f a, R \cdot T \cdot s f a, R$, and $R \cdot T$ to be endogenous variables. This means that all possible lags until $t-1$ of these variables in levels are included as instruments for these endogenous variables.

\subsection{The effect of fiscal rules}

The basic empirical results are shown in Table (2).

\section{Insert Table 2 around here}

\footnotetext{
${ }^{14}$ An extension of the instrument set to all possible lags did not change any of our results. A reduction of lags also has robust results.
} 
Stock-flow adjustments, as the accounting identity suggests, contribute to the change in the debt level with a coefficient close to one, the 95 percent confidence interval for regression 1 is [0.819,0.992]. Increasing the stock-flow adjustment per GDP by 1 percentage point results in roughly one additional percentage point debt level per GDP. However, this changes in the second period, when an increase in the stock-flow adjustment results in $\alpha_{1}+\alpha_{3}$ additional debt, and stock-flow adjustments do not translate into higher debt on a one to one basis. As the coefficient $\alpha_{1}$ is statistically not different from 1 , the estimated coefficient $\alpha_{3}$ represents the covariance between stock-flow adjustments and the deficit in the second period, which we find to be significantly negative. In regression (1) of Table (2), an increase of sfa by 1 percentage point results in a -0.25 percentage point lowering of the deficit. This suggests that stock-flow adjustments has become a policy variable to control the deficit in the time period when the fiscal rule was in place. In the earlier period, the regression results do not imply any correlation between stock-flow adjustment and deficits. Thus, our results indicate that the introduction of the fiscal rule led governments to systematically use stock-flow adjustments to lower deficits. $^{15}$

To check the robustness of our results, we omit a number of countries and observations. Finland and Sweden are dropped, as Finland had positive stock-flow adjustment because of budget surpluses invested into assets, and so did Sweden in some years. We also drop Finland, Sweden, and Luxembourg, as all three countries had positive stock-flow adjustments because of asset purchases (regression 2). Also some of the Greek figures might be distorted in the early to mid-nineties, and we also know that the data in the later years were wrongly reported (regression 3). Then we also drop the three non-Euro countries, which are officially subject to the fiscal rules, however, without being subject to fines in case of non-compliance (regression 4). In a further regression, we drop Germany and France, as it might be difficult to enforce sanctions against them. They might therefore be less constrained by the fiscal rule (regression 5). We also exclude the observations from the 1980s, as in this period, the emergence of any set of rules was not discussed (regression 6). None of these control regressions changes our results. ${ }^{16}$

\footnotetext{
${ }^{15}$ It is possible that strong negative shocks to the budget induce the government to increase deficits and stockflow adjustments, thereby causing a positive correlation. Our result is strengthened, since we find the negative relationship to prevail. The systematic use of creative accounting thus outweighs possible shocks (e.g., resulting from control errors) affecting the deficit and stock-flow adjustments in the same direction.

${ }^{16}$ With the robustness check, we show that the significance of our regression coefficients does not depend on the choice of countries and methods. It is not possible, however, to compare the magnitude of the regression coefficients, since the standard errors are too large.
} 
The results based on regression equation (9) confirm this finding and are given in the appendix, Table 5. In the first period, there is no systematic relationship between stock-flow adjustment and deficits, while in the second period a negative co-variance emerges. ${ }^{17}$ An increase in the deficit by one percentage point is associated with a lowering of the stock-flow adjustments by -0.32 percentage point. This figure is also robust to changes in the sample.

We then separate the effect of the cyclically adjusted deficit and the cyclical component of the deficit (Table 3) . We use the two official measures of cyclically adjusted balances provided by the European Commission. The first is based on the output gap in a structural model, the second is based on an HP-filtered trend. ${ }^{18}$ The estimation results based on potential output are presented in the left part of the table, while trend output results are given on the right side of the table. In the regression, we include the cyclically adjusted deficit (CAD) and the cyclical part of the deficit (CD). Again the coefficient for the first period is close to 1 as we expect for the structural deficit and for the cyclical deficit. Thus, in the first period we do not find a significant correlation between deficits and stock-flow adjustments. For the second period, however, there is a clear negative correlation between the structural deficit and stock-flow adjustments for both calculation methods similar in magnitude to the previously estimated coefficient. ${ }^{19}$ The cyclical component of the deficit and stock-flow adjustments in the second period are very strongly negatively correlated. In fact, an increase in the cyclical deficit in the second period is almost completely offset by reductions in stock-flow adjustments, indicating that stock-flow adjustments are used to weaken the impact of the cycle on the deficit.

\section{Insert Table 3 around here}

Table 3 also provides robustness checks for the impact of cyclical and structural deficits on the use of stock-flow adjustments. Similar to the other robustness checks, we drop various countries from the sample. Finland, Luxembourg and Sweden are dropped because of their surpluses, Greece is dropped as data quality is problematic, Denmark, Sweden and the UK are dropped as they do not belong to the Eurozone, and finally Germany and France are dropped

\footnotetext{
${ }^{17}$ The 95 percent confidence interval for $\beta_{1}$ is [0.705;0.993]. The $H_{0}$ that $\frac{\beta_{3}}{1-P L D V}=1$ cannot be rejected with a p-value of 0.71 . The coefficient $\beta_{3}$ for the interacted term thus again measures the covariance.

${ }^{18}$ For details on the de-trending methodologies of the EU, see European Commission (2004, pp. 79).

${ }^{19}$ In most EU countries, the structural deficit represents the largest part of the total deficit.
} 
as sanctions and warning letters are difficult to enforce against them. The estimation results confirm the previous results. For the second period, there is a stong negative correlation between the cyclical part of the deficit and stock-flow adjustments for both calculation methods. Any change in the cyclical deficit is almost completely offset by a corresponding change of sfa.

To show the robustness of our results to changes in the methodology, we also report the results of a non-dynamic model, neglecting the simultaneous equation bias (Tables (6 - 8)). OLS and fixed effect regressions yielded similar results. ${ }^{20}$ To control for heteroscedasticity, we also run generalized least squares. However, Monte-Carlo simulations by Beck and Katz (1995) show that GLS provides over-optimistic standard errors in panels of our size, therefore we present the panel corrected standard error results in the Tables. Overall, the model fits the data reasonably well. The size of the coefficients is slightly larger than in the Arellano-Bond GMM estimator, as expected. In the entire investigated period, the average debt accumulation per year given stock-flow adjustments of 0 percent of GDP was roughly 4.5 percent of GDP, in the second period it went however down by almost three percentage points. In this sense the "treatment", the introduction of fiscal rules is successfully reducing debt accumulation, especially the recorded deficit. $\alpha_{3}$ remains statistically significant and negative. In the second period, an increase in the deficit by one percentage point resulted in roughly -0.3 lower deficits. The coefficients for the cyclical and structural component of the deficit are similar to the benchmark regressions. Especially the cyclical part of the deficit is offset by an equally strong movement of stock-flow adjustments.

The regression coefficients robustly indicate that governments have used stock-flow adjustments systematically to hide deficits since the fiscal rules are introduced in Europe. This is especially relevant for the cyclical component of the deficit.

\subsection{The effect of binding fiscal rules}

Our regression analysis so far shows that after the introduction of the fiscal rules, stock-flow adjustments have become a policy instrument to control the evolution of the deficit. In this section we want to extent this point and separate empirically the effect of the introduction of

\footnotetext{
${ }^{20}$ The F-test on the fixed effects indicates that country specific effects are significant.
} 
the rule from the effect the rule has on governments, when it actually constrains their intentions.

As a first test, whether the sfa increases when the constraint of the SGP becomes binding, we compare the average sfa in the group of observations with $\Delta b>3$ before and after the SGP was in place with the average of $s f a$ for the other group $(\Delta b<3)$ sfa increased more in the first group than in the second group (0.36=(2.99-2.19)-(0.94-0.5)). This indicates, that the use of $s f a$ as a way to incur new debt has especially increased in the group of countries, for which the rule on deficits is binding.

The econometric results aimed at testing whether creative accounting increases in importance, when the fiscal rules become binding, are presented in Table 4. We present panel fixed effect regressions and dynamic Arellano Bond estimation results. ${ }^{21}$

\section{Insert Table 4 around here}

The first, somewhat surprising result concerns the coefficient on $s f a$ and the deficit. It is now only 0.5 and 0.43 respectively for the whole sample. However we also find a significant interaction term $R$. sfa of 0.38 and 0.35 , where we expected a zero coefficient. This means that countries with a lower change in debt show a negative correlation between deficits and $s f a$, while for debt level changes above 3 percent we find a coefficient close to the previously estimated 1 implying no correlation between sfa and deficits. This effect is driven by budget surpluses as we conclude from a look at the scatterplots. Countries with budget surpluses in general do not use these surpluses to reduce their debt levels but instead have a tendency to buy assets. This observation is in line with our descriptive evidence of section 2.3, where the largest discrepancy between debt and accumulated deficits are observed for Finland, a country with significant surpluses.

We therefore estimate the proposed model for only those observations, where the deficit is positive (i.e., we dropped observations of budget surpluses in columns B of Table 4). Now, the coefficient on sfa has the expected value, i.e., 1, stock-flow adjustment contribute to

\footnotetext{
${ }^{21}$ In the Arellano Bond estimation procedure we addressed the endogeneity issues discussed above.
} 
increases of the debt level on a one to one basis, no negative correlation between $s f a$ and deficits exists in general.

In addition, the effect of sfa on the change in debt is the same for $\mathrm{R}=1$ and $\mathrm{R}=0$. The coefficient on sfa interacted with the dummy for the second period is insignificant. This means, that no general negative correlation between sfa and deficits can be observed in the second period.

In contrast, we find a strongly significant and negative effect for the coefficient on $s f a$ interacted with the dummy for the period when the SGP was in place and a dummy for those observations, where countries intend to increase their debt levels by more than 3 percent. This means, that for those observations, for which the rule is expected to become binding, a negative regression coefficient for $s f a$ of -0.62 is estimated, implying a negative correlation between $s f a$ and deficits in case of a binding fiscal rule.

Again, we check the robustness of the estimation results by dropping a variety of countries in the estimation. The results are presented in Table 9 in the appendix. The results confirm the result. The estimated coefficient on the simple interaction term for the second period becomes insignificant. This means, that the imposition of the SGP does not result in a significant general use of sfa to improve the budget. We find a significantly negative coefficient for the interaction term $\mathrm{R}^{*} \mathrm{~T}^{*} s f a$. This means that those governments that intend to run deficits beyond the three percent limit heavily resort to stock-flow adjustments instead of the deficit to comply with the legal limits. ${ }^{22}$

The extended estimation gives a more detailed view on the empirical effect of fiscal rules. ${ }^{23}$ The results show, that any intended increase of the debt level beyond three percent under the SGP regime was almost exclusively done by increasing stock-flow adjustments instead of officially published deficits. Stock flow adjustments were, however, not used as a general mean to reduce the deficit to comply with the pact's provision to balance the budget in the medium term. These results are in line with evidence taken from political debates. The debate among policy makers almost exclusively focussed on the "magic" three percent threshold. At this threshold, we also find creative accounting to become relevant. The robustness tests

\footnotetext{
${ }^{22}$ The same results are obtained when using deficits as the explanatory variable.

${ }^{23}$ A separate estimation of the cyclical effects for binding vs. non-binding fiscal rules was not possible because the relatively short sample period yields only few observations.
} 
further confirm that governments in general heavily resort to creative accounting in the EU, when their desired fiscal stance does not comply with the binding fiscal rule.

\section{Conclusions}

Fiscal rules are introduced to constrain governments. EU countries have adopted a set of rules to constrain deficits with the goal to keep debt levels sustainable. We have given evidence that deficits in Europe provide only limited information on the evolution of debt levels in the past.

We then have tested the hypothesis that governments try to circumvent fiscal rules by means of creative accounting. Our empirical evidence indicates that the introduction of the Stability and Growth Pact and the Excessive Deficit Procedure in Europe have resulted in creative accounting. While stock-flow adjustments have significantly contributed to debt accumulation in the last twenty years in Europe, only after the introduction of the fiscal framework in Europe a systematic relationship between these adjustments and deficits can be detected. Furthermore, this use of creative accounting is especially responsive to cyclical parts of the deficit, where the associated costs of the non-state-contingent fiscal rule are high. The use of creative accounting is especially measurable, when the fiscal rules become binding. Our results confirm the vulnerability of fiscal rules due to creative accounting. 


\section{References}

Arellano, M., Bond, S.,1991. Some Tests of Specification for Panel Data: Monte Carlo Evidence and an Application to Employment Equations, Review of Economic Studies, 58, 277--297.

Balassone, F., Franco, D., Zotteri, S., 2004. EMU Fiscal Indicators: A Misleading Compass?, WP.

Beck, N., Katz, J., 1995. What to Do (and Not to Do) with Time-Series and Cross-Section Data, American Political Science Review, 89, 634--647.

Blejer, M., Cheasty, A., 1991. The Measurement of Fiscal Deficits: Analytical and Methodological Issues, Journal of Economic Literature, 24, 1644--1678.

Bohn, H., Inman, R. P., 1996. Balanced Budget Rules and Public Deficits: Evidence from the U.S. States, NBER Working Paper, 5533.

Bunch, B. S., 1991. The Effect of Constitutional Debt Limits on State Governments' Use of Public Authorities, Public Choice, 68, 57--69.

Dafflon, B., Rossi, S., 1999. Public Accounting Fudges Towards EMU: A First Empirical Survey and some Public Choice Considerations,’Public Choice, 101, 59--84.

ECB, 2004. Monthly Bulletin March. European Central bank, Frankfurt am Main.

European Comission, 2004. Public Finances in EMU 2004. The European Commission, Brussels.

European Comission, DG for Economic and Financial Affairs, 2003. Public Finances in EMU 2003. The European Commission, Brussels.

Eurostat, 2002. ESA95 Manual on Government Deficits and Debt. Office for Official Publications of the European Communities, Luxembourg.

Greene, W. H., 2000. Econometric Analysis. Prentice Hall International, London etc.

Gujarati, D. N., 1995. Basic Econometrics, Third Edition. McGraw-Hill Book Co., New York.

Kiewiet, D., Szakaly, K., 1996. Constitutional Limitations on Borrowing: Analysis of State Bonded Indebtedness, Journal of Economics, Law, and Organization, April, 62--97.

Laughland, J., Paul, J.-M., 1997. Belgium Cooks its EMU Books, The Wall Street Journal Europe, January 9.

Milesi-Ferretti, G., 2003. Good, Bad or Ugly? On the Effects of Fiscal Rules with Creative Accounting, Journal of Public Economics, 88, 377--394. 
Milesi-Ferretti, G., Moriyama, K., 2004. Fiscal Adjustment in EU Countries: A Balance Sheet Approach, IMF Working Paper, 04/143.

Münster, W., 1997. Das Spiel mit den Defiziten., Süddeutsche Zeitung, 23. August. In: Deutsche Bundesbank, Auszüge aus Presseartikeln.

Poterba, J. M.,1994. State Responses to Fiscal Crises: The Effects of Budgetary Institutions and Politics, Journal of Political Economy, 102 (4), 799--821.

Sbragia, A., 1996. Debt Wish. University of Pittsburgh Press, Pittsburgh.

Strauch, R. R., 1998. Budget Processes and Fiscal Discipline: Evidence from the US States, ZEI working paper.

von Hagen, J., 1991. A Note on the Empirical Effectiveness of Formal Fiscal Restraints, Journal of Public Economics, 44, 199--210.

von Hagen, J., 2002. Fiscal Rules, Fiscal Institutions, and Fiscal Performance,’The Economic and Social Review, 33 (3), 263--84.

von Hagen, J., Harden, I. J., 1995. Budget Processes and Commitment to Fiscal Discipline, European Economic Review, 39, 771--779.

von Hagen, J., Harden, I. J., 1996. Budget Processes and Commitment to Fiscal Discipline, IMF Working Paper, 96/78. 
Table 1: Debt and accumulated deficits in percent of GDP

\begin{tabular}{lcccc}
\hline Country & debt, 1980 & debt, 2003 & sum of deficits & difference \\
\hline & $\mathrm{A}$ & $\mathrm{B}$ & $\mathrm{C}$ & $\mathrm{B}-\mathrm{C}$ \\
\hline Austria & 36 & 66 & 52 & 14 \\
Belgium & 79 & 103 & 100 & 3 \\
Denmark & 36 & 43 & 13 & 30 \\
Finland & 11 & 45 & -19 & 64 \\
France & 20 & 63 & 54 & 9 \\
Germany & 31 & 64 & 49 & 15 \\
Greece & 25 & 101 & 58 & 43 \\
Ireland & 75 & 33 & 25 & 8 \\
Italy & 58 & 106 & 99 & 7 \\
Luxembourg & 9 & 5 & -24 & 29 \\
Netherlands & 46 & 55 & 53 & 2 \\
Portugal & 32 & 58 & 53 & 5 \\
Spain & 17 & 51 & 47 & 4 \\
Sweden & 40 & 52 & 50 & 2 \\
United Kingdom & 53 & 40 & 39 & 1 \\
\hline Source: Ammat
\end{tabular}

Source: Ameco, own calculations; The accumulated absolute deficits were added to the initial debt level of 1980 (column A) for all countries, except Greece (1988), Luxembourg and Ireland (1990), Sweden (1993), and Spain (1995) due to data constraints. This cumulative debt measure was divided by GDP of 2003. 
Table 2: Measuring the impact of fiscal rules.

\begin{tabular}{|c|c|c|c|c|c|c|c|}
\hline$\Delta b_{\text {it }}$ & 1 & 2 & 3 & 4 & 5 & 6 & 7 \\
\hline \multirow[t]{2}{*}{ sfa } & 0.91 & 0.95 & 0.97 & 0.94 & 0.88 & 0.89 & 0.95 \\
\hline & 0.04 & 0.04 & 0.04 & 0.05 & 0.05 & 0.05 & 0.05 \\
\hline \multirow[t]{2}{*}{$\mathrm{T}$} & -1.55 & -1.11 & -1.31 & -1.16 & -0.88 & -1.84 & -0.91 \\
\hline & 0.33 & 0.31 & 0.32 & 0.31 & 0.37 & 0.37 & 0.42 \\
\hline \multirow[t]{2}{*}{$T^{*}$ sfa } & -0.25 & -0.40 & -0.38 & -0.33 & -0.32 & -0.18 & -0.36 \\
\hline & 0.08 & 0.09 & 0.10 & 0.10 & 0.09 & 0.08 & 0.08 \\
\hline \multirow[t]{2}{*}{ cons } & 0.04 & -0.02 & -0.01 & 0.00 & 0.00 & 0.03 & -0.14 \\
\hline & 0.03 & 0.03 & 0.03 & 0.03 & 0.03 & 0.03 & 0.05 \\
\hline \multirow[t]{2}{*}{ LDV } & 0.51 & 0.45 & 0.44 & 0.46 & 0.53 & 0.50 & 0.41 \\
\hline & 0.03 & 0.03 & 0.03 & 0.03 & 0.03 & 0.03 & 0.04 \\
\hline obs. & 263 & 233 & 221 & 220 & 212 & 221 & 183 \\
\hline $\begin{array}{l}\text { Sargan } p \\
\text { Autocorr2, } p\end{array}$ & $\begin{array}{l}0.88 \\
0.50\end{array}$ & $\begin{array}{l}0.98 \\
0.86\end{array}$ & 0.990 .80 & 1.000 .75 & 1.000 .75 & $\begin{array}{l}1.00 \\
0.43\end{array}$ & $\begin{array}{l}0.99 \\
0.87\end{array}$ \\
\hline omitted & & SE,FI & SE,FI,LU & SE,FI,GR & SE,DK,UK & $\mathrm{DE}, \mathrm{FR}$ & $<1991$ \\
\hline
\end{tabular}

Note: Dependent variable: Change in the debt relative to GDP. T=1 if year>1997. LDV refers to the lagged dependent variable. Last line refers to which observations were omitted. Standard errors are reported below the coefficients. Method:

Arellano Bond dynamic GMM panel estimator. 
Table 3: Measuring the impact of fiscal rules on the cyclical component of the deficit

\begin{tabular}{|c|c|c|c|c|c|c|c|c|c|c|c|}
\hline \multicolumn{6}{|l|}{$\Delta b_{i t}$} & \multicolumn{6}{|l|}{$\Delta \mathrm{b}$} \\
\hline \multirow[t]{2}{*}{ CAD1 } & 0.82 & 0.89 & 0.81 & 0.78 & 0.75 & CAD2 & 0.80 & 0.91 & 0.85 & 0.81 & 0.79 \\
\hline & 0.07 & 0.09 & 0.07 & 0.08 & 0.08 & & 0.08 & 0.09 & 0.07 & 0.08 & 0.08 \\
\hline \multirow[t]{2}{*}{$\mathrm{T}^{\star} \mathrm{CAD} 1$} & -0.20 & -0.16 & -0.23 & -0.24 & -0.23 & $T^{*} \mathrm{CAD} 2$ & -0.21 & -0.15 & -0.21 & -0.23 & -0.20 \\
\hline & 0.12 & 0.17 & 0.11 & 0.13 & 0.14 & & 0.12 & 0.17 & 0.11 & 0.14 & 0.14 \\
\hline \multirow[t]{2}{*}{ CD1 } & 1.01 & 1.41 & 1.18 & 1.03 & 1.28 & CD2 & 1.15 & 1.34 & 1.03 & 0.88 & 1.14 \\
\hline & 0.13 & 0.19 & 0.12 & 0.15 & 0.15 & & 0.13 & 0.19 & 0.12 & 0.14 & 0.14 \\
\hline \multirow[t]{2}{*}{$\mathrm{T}^{\star} \mathrm{CD} 1$} & -0.83 & -0.91 & -0.87 & -0.64 & $-1,05$ & $\mathrm{~T}^{\star} \mathrm{CD} 2$ & -0.88 & -0.89 & -0.81 & -0.53 & -1.03 \\
\hline & 0.25 & 0.31 & 0.22 & 0.27 & 0.27 & & 0.33 & 0.24 & 0.22 & 0.29 & 0.29 \\
\hline \multirow[t]{2}{*}{$\mathrm{T}$} & 1.44 & 1.53 & 1.63 & 1.30 & 1.79 & $\mathrm{~T}$ & 1.42 & 1.59 & 1.67 & 1.32 & 1.80 \\
\hline & 0.49 & 0.57 & 0.43 & 0.52 & 0.54 & & 0.48 & 0.57 & 0.43 & 0.54 & 0.54 \\
\hline \multirow[t]{2}{*}{ Cons } & 0.19 & -0.16 & -0.20 & -0.18 & -0.25 & cons & 0.18 & -0.18 & -0.21 & -0.18 & -0.26 \\
\hline & 0.03 & 0.04 & 0.03 & 0.04 & 0.04 & & 0.03 & 0.04 & 0.03 & 0.04 & 0.04 \\
\hline \multirow[t]{2}{*}{ LDV } & 0.17 & 0.15 & 0,15 & 0.16 & 0.13 & LDV & 0.17 & 0.14 & 0.15 & 0.17 & 0.13 \\
\hline & 0.05 & 0.06 & 0.05 & 0.06 & 0.06 & & 0.05 & 0.06 & 0.05 & 0.06 & 0.06 \\
\hline Obs & 263 & 221 & 250 & 212 & 221 & & 263 & 221 & 250 & 212 & 221 \\
\hline $\begin{array}{l}\text { Sargan } \\
\text { Autocorr }\end{array}$ & 1 & 1 & 0.79 & 0.99 & 0.99 & & 1 & 1 & 0.78 & 0.99 & 0.99 \\
\hline & 0.59 & 0,31 & 0.94 & 0.65 & 0.67 & & 0.59 & 0.34 & 0.92 & 0.66 & 0.66 \\
\hline Omitted & & FI, LU. SW & GR & DK, SW,UK & $\mathrm{DE}, \mathrm{FR}$ & & & FI,LU, SW & GR & DK,SW,UK & DE,FR \\
\hline
\end{tabular}

Note: Dependent variable: Change in the debt relative to GDP. T=1 if year>1997. LDV refers to the lagged dependent variable.

CAD1=Cyclically Adj. Deficit, CD1= Cyclical component both based on potential output. CAD2=Cyclically Adj. Deficit, CD2=Cycli-

cal component both based on HP filtered output trend. Standard errors are reported below the coefficients. Method: Arellano Bond dynamic

GMM panel estimator. Deficit, and interaction term specified as endogenous variables. 
Table 4: Measuring the impact of binding fiscal rules

\begin{tabular}{|c|c|c|c|c|}
\hline$\Delta b_{\text {it }}$ & fixed effect & Arellano-Bond & fixed effect & Arellano-Bond \\
\hline \multirow[t]{2}{*}{ sfa } & 0.40 & 0.50 & 1.06 & 0.95 \\
\hline & 0.12 & 0.08 & 0.21 & 0.14 \\
\hline \multirow[t]{2}{*}{$R^{*} s f a$} & 0.54 & 0.38 & -0.09 & -0.03 \\
\hline & 0.13 & 0.09 & 0.22 & 0.14 \\
\hline \multirow[t]{2}{*}{$T^{\star} \mathrm{sfa}$} & 0.12 & -0.03 & -0.23 & -0.11 \\
\hline & 0.15 & 0.10 & 0.42 & 0.26 \\
\hline \multirow[t]{2}{*}{$T^{\star} R^{\star} s f a$} & -1.14 & -0.51 & -0.89 & -0.62 \\
\hline & 0.28 & 0.18 & 0.49 & 0.29 \\
\hline \multirow[t]{2}{*}{$\mathrm{R}$} & 3.67 & 2.24 & 2.83 & 1.46 \\
\hline & 0.39 & 0.27 & 0.45 & 0.30 \\
\hline \multirow[t]{2}{*}{$\mathrm{T}$} & -1.56 & -0.63 & -1.28 & -0.24 \\
\hline & 0.39 & 0.31 & 0.54 & 0.40 \\
\hline \multirow[t]{2}{*}{$T * R$} & -0.95 & -0.22 & -0.87 & 0.24 \\
\hline & 0.96 & 0.61 & 1.02 & 0.63 \\
\hline \multirow[t]{2}{*}{ cons } & 2.03 & 0.02 & 3.31 & -0.06 \\
\hline & 0.28 & 0.02 & 0.38 & 0.03 \\
\hline \multirow[t]{2}{*}{ LDV } & & 0.41 & & 0.37 \\
\hline & & 0.03 & & 0.03 \\
\hline obs & 293 & 263 & 225 & 180 \\
\hline $\mathrm{R}^{2}$ & 0.74 & & 0.77 & \\
\hline Sargan & & 0.32 & & 0.95 \\
\hline autocorr $2, p$ & & 0.79 & & 0.68 \\
\hline omitted observations & none & none & budget surplus & budget surplus \\
\hline
\end{tabular}


Appendix

Table 5: Measuring the impact of fiscal rules

\begin{tabular}{|c|c|c|c|c|c|c|c|}
\hline$\Delta \mathrm{b}_{\text {it }}$ & 1 & 2 & 3 & 4 & 5 & 6 & 7 \\
\hline \multirow[t]{2}{*}{ deficit } & 0.85 & 0.88 & 0.91 & 0.91 & 0.81 & 0.84 & 0.88 \\
\hline & 0.07 & 0.08 & 0.09 & 0.08 & 0.08 & 0.08 & 0.10 \\
\hline \multirow[t]{2}{*}{$\mathrm{T}$} & 1.81 & 1.77 & 1.87 & 1.91 & 1.50 & 2.14 & 1.38 \\
\hline & 0.46 & 0.48 & 0.52 & 0.41 & 0.49 & 0.53 & 0.65 \\
\hline \multirow[t]{2}{*}{$T^{\star}$ deficit } & -0.32 & -0.27 & -0.23 & -0.27 & -0.28 & -0.31 & -0.36 \\
\hline & 0.10 & 0.12 & 0.15 & 0.11 & 0.11 & 0.12 & 0.12 \\
\hline \multirow[t]{2}{*}{ cons } & -0.19 & -0.16 & -0.17 & -0.16 & -0.17 & -0.23 & -0.18 \\
\hline & 0.03 & 0.04 & 0.04 & 0.03 & 0.04 & 0.04 & 0.08 \\
\hline \multirow[t]{2}{*}{ LDV } & 0.17 & 0.20 & 0.18 & 0.22 & 0.18 & 0.17 & 0.08 \\
\hline & 0.05 & 0.06 & 0.06 & 0.05 & 0.06 & 0.06 & 0.07 \\
\hline obs. & 263 & 233 & 221 & 220 & 212 & 221 & 183 \\
\hline Sargan $p$ & 1 & 1.00 & 1.00 & 1.00 & 1.00 & 1.00 & 1.00 \\
\hline Autocorr 2, p & 0.76 & 0.34 & 0.34 & 0.44 & 0.68 & 0.83 & 0.80 \\
\hline omitted & & SE, FI & SE, FI, LU & SE, FI, GR & SE, DK, UK & $\mathrm{DE}, \mathrm{FR}$ & $<1991$ \\
\hline
\end{tabular}

Note: Dependent variable: Change in the debt relative to GDP. $T=1$ if year>1997. LDV

refers to the lagged dependent variable. Last line refers to which observations were omitted. Standard errors are reported below the coefficients. Method: Arellano Bond dynamic GMM panel estimator. 
Table 6: Robustness check: Measuring the impact of fiscal rules with different methodologies.

\begin{tabular}{|c|c|c|c|c|c|c|c|c|c|}
\hline$\Delta b_{\text {it }}$ & OLS & FE & $\begin{array}{c}\text { PCS } \\
\text { E }\end{array}$ & $\Delta b_{i t}$ & OLS & FE & $\begin{array}{c}\text { PCS } \\
\text { E }\end{array}$ & PCSE & PCSE \\
\hline \multirow[t]{2}{*}{ sfa } & 0.96 & 1.07 & 0.98 & deficit & 0.98 & 1.04 & 1.01 & & \\
\hline & 0.09 & 0.07 & 0.05 & & 0.05 & 0.06 & 0.08 & & \\
\hline \multirow[t]{2}{*}{$\mathrm{T}$} & -3.56 & -3.63 & -2.37 & $\mathrm{~T}$ & -0.4 & -0.16 & -0.2 & -0.53 & -0.52 \\
\hline & 0.54 & 0.38 & 0.78 & & 0.4 & 0.39 & 0.57 & 0.61 & 0.59 \\
\hline \multirow[t]{2}{*}{$T^{\star}$ sfa } & -0.53 & -0.41 & -0.32 & $T^{\star}$ deficit & -0.46 & -0.46 & -0.47 & & \\
\hline & 0.19 & 0.13 & 0.11 & & 0.12 & 0.11 & 0.13 & & \\
\hline \multirow[t]{10}{*}{ cons } & 4.34 & 4.15 & 4.13 & cons & 1.73 & 1.48 & 1.07 & 1.11 & 1.24 \\
\hline & 0.3 & 0.21 & 0.93 & & 0.28 & 0.29 & 0.66 & 0.52 & 0.53 \\
\hline & & & & CAB & & & & 1 & 0.95 \\
\hline & & & & & & & & 0.069 & 0.07 \\
\hline & & & & $T^{\star} \mathrm{CAB}$ & & & & -0.34 & -0.34 \\
\hline & & & & & & & & 0.15 & 0.15 \\
\hline & & & & $C D$ & & & & 1.21 & 1.39 \\
\hline & & & & & & & & 0.17 & 0.17 \\
\hline & & & & $\mathrm{T}^{\star} \mathrm{CD}$ & & & & -0.98 & -1.12 \\
\hline & & & & & & & & 0.36 & 0.34 \\
\hline $\mathrm{R}^{2}$ & 0.43 & 0.61 & 0.71 & $\mathrm{R}^{2}$ & 0.69 & 0.67 & 0.71 & 0.79 & 0.79 \\
\hline obs & 293 & 293 & 293 & observations & 293 & 293 & 293 & 293 & 293 \\
\hline ctr. d. & no & no & yes & $\begin{array}{l}\text { ctr. d. } \\
\text { output }\end{array}$ & no & no & yes & $\begin{array}{c}\text { yes } \\
\text { trend }\end{array}$ & $\begin{array}{c}\text { yes } \\
\text { potential }\end{array}$ \\
\hline
\end{tabular}

Note: Dependent variable: Change in the debt relative to GDP. T=1 if year>1997. In the panel corrected standard error (PCSE) regressions we took account of possible autocorrelation in the error term. FE refers to standard fixed effect regressions. 
Table 7: Robustness check: Measuring the impact of fiscal rules

\begin{tabular}{|c|c|c|c|c|c|c|}
\hline$\Delta \mathrm{b}_{\text {it }}$ & PCSE & PCSE & PCSE & PCSE & PCSE & PCSE \\
\hline \multirow[t]{2}{*}{ sfa } & 1.00 & 1.02 & 1.09 & 0.94 & 0.98 & 1.03 \\
\hline & 0.06 & 0.06 & 0.07 & 0.06 & 0.06 & 0.06 \\
\hline \multirow[t]{2}{*}{$\mathrm{T}$} & -2.31 & -2.56 & -2.13 & -2.18 & -2.94 & -2.82 \\
\hline & 0.69 & 0.70 & 0.64 & 0.69 & 0.82 & 0.79 \\
\hline \multirow[t]{2}{*}{$T^{*}$ sfa } & -0.39 & -0.39 & -0.41 & -0.33 & -0.3 & -0.44 \\
\hline & 0.12 & 0.14 & 0.14 & 0.13 & 0.12 & 0.11 \\
\hline \multirow{2}{*}{ cons } & 4.08 & 4.25 & 3.92 & 4.03 & 4.45 & 4.35 \\
\hline & 0.84 & 0.85 & 0.84 & 0.87 & 0.88 & 0.78 \\
\hline $\mathrm{R}^{2}$ & 0.75 & 0.76 & 0.71 & 0.71 & 0.72 & 0.77 \\
\hline obs & 259 & 245 & 244 & 236 & 247 & 189 \\
\hline $\begin{array}{r}\text { ctr. } \\
\text { dummies }\end{array}$ & yes & yes & yes & yes & yes & yes \\
\hline ommitted & $\mathrm{SE}, \mathrm{FI}$ & SE, FI, LU & SE, FI, GR & DE, FR & SE, DK, UK & $<1990$ \\
\hline
\end{tabular}


Table 8: Robustness check: Measuring the impact of fiscal rules

\begin{tabular}{lcccccc}
\hline$\Delta \mathrm{b}_{\text {it }}$ & PCSE & PCSE & PCSE & PCSE & PCSE & PCSE \\
\hline deficit & $\mathbf{1 . 1 1}$ & $\mathbf{1 . 1 4}$ & $\mathbf{1 . 1 8}$ & $\mathbf{0 . 9 7}$ & $\mathbf{1}$ & $\mathbf{1 . 0 6}$ \\
$\mathrm{T}$ & 0.09 & 0.10 & 0.08 & 0.08 & 0.08 & 0.11 \\
& $\mathbf{0 . 1 1}$ & $\mathbf{0 . 2 3}$ & $\mathbf{0 . 3 2}$ & $\mathbf{- 0 . 3 6}$ & $\mathbf{- 0 . 2 3}$ & $\mathbf{0 . 6 1}$ \\
$\mathrm{T}{ }^{*}$ deficit & 0.53 & 0.66 & 0.51 & 0.51 & 0.68 & 0.6 \\
& $\mathbf{- 0 . 4 4}$ & $\mathbf{- 0 . 3 8}$ & $\mathbf{- 0 . 4 9}$ & $\mathbf{- 0 . 4 1}$ & $\mathbf{- 0 . 4 8}$ & $\mathbf{- 0 . 5}$ \\
cons & 0.12 & 0.17 & 0.11 & 0.13 & 0.15 & 0.16 \\
& $\mathbf{0 . 6 4}$ & $\mathbf{0 . 4 6}$ & $\mathbf{0 . 3 5}$ & $\mathbf{1 . 2 4}$ & $\mathbf{1 . 1 1}$ & $\mathbf{0 . 4 6}$ \\
\hline $\mathrm{R}^{2}$ & 0.64 & 0.69 & 0.63 & 0.63 & 0.73 & 0.61 \\
observations & 0.75 & 0.75 & 0.75 & 0.74 & 0.71 & 0.74 \\
\hline ommitted & $\mathrm{SE}, \mathrm{FI}$ & $\mathrm{SE}, \mathrm{FI}$, & $\mathrm{SE}, \mathrm{FI}$, & $\mathrm{DE}, \mathrm{FR}$ & $\mathrm{SE}, \mathrm{DK}$, & $<1990$ \\
& & $\mathrm{LU}$ & $\mathrm{GR}$ & & $\mathrm{UK}$ & \\
\hline
\end{tabular}

Note: Dependent variable: Change in the debt relative to GDP. T=1 if year>1997. All regressions include country dummies. In the panel corrected standard error (PCSE) regressions we took account of possible autocorrelation in the error term. 
Table 9: Robustness check: Measuring the impact of binding fiscal rules

\begin{tabular}{|c|c|c|c|c|c|c|c|c|}
\hline$\Delta b_{i t}$ & FE & $A B$ & FE & $A B$ & FE & $A B$ & FE & $A B$ \\
\hline \multirow{2}{*}{ sfa } & 0.80 & 0.74 & 0.40 & 0.50 & 0.38 & 0.46 & 0.39 & 0.49 \\
\hline & 0.20 & 0.13 & 0.12 & 0.08 & 0.13 & 0.09 & 0.12 & 0.09 \\
\hline \multirow[t]{2}{*}{$R^{*}$ sfa } & 0.21 & 0.12 & 0.53 & 0.34 & 0.58 & 0.43 & 0.53 & 0.36 \\
\hline & 0.21 & 0.13 & 0.13 & 0.09 & 0.14 & 0.10 & 0.13 & 0.09 \\
\hline \multirow[t]{2}{*}{$D^{*} \mathrm{sfa}$} & -0.29 & -0.21 & 0.12 & -0.04 & 0.09 & -0.07 & 0.20 & 0.04 \\
\hline & 0.28 & 0.18 & 0.15 & 0.10 & 0.16 & 0.11 & 0.16 & 0.11 \\
\hline \multirow[t]{2}{*}{$R^{\star} D^{\star} s f a$} & -0.83 & -0.52 & -0.95 & -0.24 & -1.18 & -0.65 & -0.96 & -0.43 \\
\hline & 0.39 & 0.25 & 0.35 & 0.22 & 0.32 & 0.21 & 0.32 & 0.21 \\
\hline \multirow[t]{2}{*}{$\mathrm{R}$} & 3.04 & 1.99 & 3.65 & 2.26 & 3.37 & 1.89 & 4.29 & 2.69 \\
\hline & 0.44 & 0.29 & 0.39 & 0.27 & 0.44 & 0.31 & 0.44 & 0.31 \\
\hline \multirow[t]{2}{*}{ D } & -1.79 & -0.47 & -1.55 & -0.61 & -1.40 & -0.13 & -1.70 & -0.79 \\
\hline & 0.44 & 0.35 & 0.38 & 0.31 & 0.46 & 0.35 & 0.45 & 0.35 \\
\hline \multirow[t]{2}{*}{$R^{\star} D$} & -0.43 & 0.19 & -0.70 & -0.19 & -0.87 & 0.22 & -2.30 & -1.07 \\
\hline & 0.99 & 0.61 & 0.97 & 0.62 & 1.01 & 0.65 & 1.24 & 0.79 \\
\hline \multirow[t]{2}{*}{ cons } & 2.76 & -0.01 & 1.76 & 0.03 & 2.38 & -0.02 & 1.91 & 0.03 \\
\hline & 0.35 & 0.02 & 0.27 & 0.02 & 0.33 & 0.03 & 0.32 & 0.03 \\
\hline \multirow[t]{2}{*}{ LDV } & & 0.39 & & 0.42 & & 0.43 & & 0.39 \\
\hline & & 0.03 & & 0.03 & & 0.03 & & 0.03 \\
\hline obs & 245 & 221 & 278 & 250 & 236 & 212 & 247 & 221 \\
\hline $\mathrm{R}^{2}$ & 0.77 & & 0.73 & & 0.73 & & 0.77 & \\
\hline Sargan & & 0.86 & & 0.85 & & 0.99 & & 0.94 \\
\hline autocorr 2 & & 0.67 & & 0.90 & & 0.78 & & 0.82 \\
\hline ommitted & $\begin{array}{c}\text { FI, LU, } \\
\text { SW }\end{array}$ & & GR & & $\begin{array}{c}\text { DK, } \\
\text { SW, UK }\end{array}$ & & $\mathrm{DE}, \mathrm{FR}$ & \\
\hline
\end{tabular}

Note: Dependent variable: Change in the debt relative to GDP. $T=1$ if year>1997. $R=1$ if $\Delta b>3$, LDV refers to the lagged dependent variable. Standard errors are reported below the coefficients. Methods: Panel fixed effect (FE) and Arellano Bond dynamic GMM panel estimator (AB). 